\title{
Electrochemical Aptasensor based on the Hybridization Chain Reaction for Kanamycin Detection
}

\author{
Qinpu Zhang ${ }^{1}$, Fang Li $^{1,2, *}$, Xinmiao Li ${ }^{1}$, Yunhong Liu ${ }^{1,2, *}$, Jing Han ${ }^{1}$ \\ ${ }^{1}$ College of Food and Biological Engineering, Henan University of Science and Technology, Luoyang \\ 471023, China \\ ${ }^{2}$ National Experimental Teaching Demonstration Center of Food Processing and Security, Henan \\ University of Science and Technology, Luoyang 471023, P. R. China \\ *E-mail: lifang182006@126.com, lyunhong@126.com
}

Received: 1 August 2021 / Accepted: 9 September 2021 / Published: 10 October 2021

\begin{abstract}
In this work, a novel electrochemical aptamer sensor was fabricated for the sensitive and label-free detection of kanamycin in milk. The kanamycin aptamer was fixed on the magnetic nanoparticle for capturing kanamycin or complementary probe. The complementary probe and a pair of hairpin probes were used as initiators for the hybridization chain reaction. Methylene blue was used as electroactive indicator for electrochemical detection. Under optimal experimental conditions, the aptamer sensor has a good linear relationship with kanamycin concentration in the range of $1.0 \times 10^{-12}$ to $1.0 \times 10^{-7} \mathrm{~mol} / \mathrm{L}$. The detection limit of the aptamer sensor is $1.0 \times 10^{-12} \mathrm{~mol} / \mathrm{L}(\mathrm{S} / \mathrm{N}=3)$. The proposed method can be successfully applied for the detection of kanamycin in milk.
\end{abstract}

Keywords: kanamycin; aptamer; hybridization chain reaction

\section{FULL TEXT}

(C) 2021 The Authors. Published by ESG (www.electrochemsci.org). This article is an open access article distributed under the terms and conditions of the Creative Commons Attribution license (http://creativecommons.org/licenses/by/4.0/). 